\title{
How does the pandemic has affected the economic sustainability of Textile industry in France?
}

\author{
Eleonora Santos ${ }^{1, *}$ \\ ${ }^{1}$ Centre of Applied Research in Management and Economics, Polytechnic Institute of Leiria, Portugal
}

\begin{abstract}
Research background: France is one of the leading textile manufacturers in Europe. However, the COVID-19 pandemic has challenged the current practices in the industry. The lack of crisis management characterized by delayed payments, order cancellations, fixed costs, and other unpredictable expenses, turned it difficult for firms to guarantee liquidity and to preserve their economic sustainability.

Purpose of the article: To analyse how the pandemic has affected the economic sustainability of Textile industry in France.

Methods: Using the financial reports of 57 French firms operating in Textile industry, in 2018-2020, from ORBIS, a financial analysis is performed using the ratios of profitability, liquidity and indebtedness, as well as the profit margin and labour productivity to evaluate how these firms have been tackling the challenges of the recent crisis; and, thus, evaluate their economic sustainability.

Findings \& Value added: Results suggest that micro firms and SMEs have better financial profitability, display higher levels of liquidity, are less indebted and are more capable to increase their profit margins. Yet, the larger firm shows a higher level of labour productivity, followed by the micro enterprises. Thus, smaller French textile firms appear to be more economically sustainable during the pandemic. This might suggest that smaller firms are more flexible, resilient, and capable to quickly adapt their operations to market's needs. Such findings provide policy insights on the implementation of the appropriate strategies during times of crisis.
\end{abstract}

Keywords: Covid-19; economic sustainability; France; textile industry

JEL Classification: D24; F61; G30

\footnotetext{
* Corresponding author: eleonora.santos@ipleiria.pt
} 


\section{Introduction}

France is one of the largest net exporters in the garment and is regarded as the capital of world fashion. Thus, many world brands acknowledged by their qualities and authenticity are in Paris. However, recently, the Fashion industry underwent major changes with the development of the circular economy. Accordingly, academic researchers propose methods to develop a more circular and sustainable textile economy (Kozlowski, Searcy and Bardecki 2018) and changes in the whole life cycle of textiles have been implemented. In addition, the Textile industry faces a fierce international competition due to globalisation. Firms are scattered around the territory, covering the regions of Normandy to Picardy, the North, the Ardennes, Champagne, Alsace, and Lyons. The textiles comprise three main branches: the yarn; the weaving and the fabric finishing. The industry although large, is led by several small firms selling a small quantity of highly technical and high value products. In 2018, the French textile industry was comprised of approximately 548 firms with 20 employees on average. The manufacturing of apparel accounts nearly $45 \%$ of the market's total value, while fabrics represent about $30 \%$. The country is one of the leading technical textile manufacturers in Europe together with Germany and Italy.

The textile industry contributes with $7 \%$ of the total world exports and employs over 35,000 thousand workers worldwide (Desore and Narula 2018; Costa et al., 2020). However, the COVID-19 pandemic has substantially disrupted the industry supply chain. In May and June 2020, the expected turnover decreased in 32\% (Zao and Kim, 2021). This period is characterized by an unusual market situation with almost no research on how the industry can recover. It is, therefore, important to evaluate these firms' economic sustainability.

The textiles have suffered major impacts due to Covid-19 pandemic. The lockdown in China, the world's largest textile producer caused delays in the manufacturing supply chain. The following large-scale order cancellations and postponements affected vendors in Southeast Asia (ITMF, 2020). Furthermore, firms operating in China or South Korea faced labour and raw materials shortages and a significant increase in shipping and logistics costs ( $\mathrm{Lu}, 2020)$. The lack of consumer demand, due to forced lockdown, and travel restrictions preventing fashion consumers to purchase in fashion capitals have severely damaged corporate businesses (Achille \& Zipser, 2020; McIntosh, 2020). Moreover, the lack of crisis management turned it difficult for firms to guarantee liquidity during the pandemic (ITMF, 2020). Because of delayed payment, order cancellations, fixed costs and other unpredictable expenses, firms are experiencing difficulties to preserve their economic sustainability. To make things worse, the strong competitive pressure created by cheap labour economies; global scale fluctuation between offer and demand (Araújo et al, 2019); and other problems related to the evolution of technology and changes in consumers' preferences, for example due to the implementation of the circular economy practices; compel the textile industry to face an enormous volatility regarding its economic performance. The combination of these adverse factors, demand for a new competitive dynamics and flexibility, regarding products, processes, and management structures.

However, the crisis has also created opportunities. For example, in the Centro region of Portugal, firms had quickly adapted their resources to manufacture face masks and other personal protective equipment (PPE) responding to other sectors' needs. A financial analysis of firms operating in textiles provides insights for early identify which resources to procure and produce during and after the pandemic. Thus, this paper contributes to explore the impact of recent changes on firms' economic sustainability. The paper consists of five parts.; Section 2 reviews the literature on financial performance of textile industry; Section 3 explains the data sources and methods, section 4 presents and discusses the results; and section 5 presents the conclusions and policy implications. 


\section{Literature review}

There is a relative extensive body of literature that analyses the impact of a specific factor on firms' performance. The inventory management is one of the most studied factors. For example, some studies suggest that a low level of an inventory improves firms' profitability, measured by earnings per share (Huson and Nanda, 1995), labour productivity (Lieberman and Demeester, 1999), ROA (Fullerton et al., 2003; Modi and Mishra, 2011), gross margin (Gaur et al.,2005) and stock returns (Chen et al., 2007; Modi and Mishra, 2011). Atypical inventory changes are negatively associated with stock returns (Steinker and Hoberg, 2013).

Bose et al. (2011) examine the impact of a disruptive technology that enables a process innovation, the radio frequency identification (RFID), on the performance of the textile industry. The results show that this technology adoption improved labour productivity (USD $3,660$ per employee), sales growth ( $2 \%)$ and ROA ( $2 \%)$ over a five-year period.

Lo et al. (2012) tested the impact of environmental management systems (EMS) adoption on the performance of fashion and textiles industries. They found that, due to improvements in cost efficiency, since they implemented ISO 14000, certified firms improved ROA (2.9\%) and return-on-sales $(3.3 \%)$ over a three-year period.

Ntsalaze, L. (2013) conducted a comparative panel study of performance between family and non-family firms in the Clothing and Textiles manufacturing industry in the South Africa, for 2009-2011. Using financial ratios such as ROA, ROE, income security cover, outside funds to cash flow and shareholders' funds to total assets, and a regression analysis to estimate the relationship between performance and firms, the author finds that family business performed better on ROA.

Dulange et al. (2014) used a Resource based View framework and a questionnaire to examine the relationship between tangibles assets, intangibles assets and capabilities on the organizational performance of 160 power loom textiles in India. They found a positive relationship between those dimensions and organizational performance.

Masud \& Islam (2018) studied the relationship between corporate social responsibility (CSR) and financial performances of textiles in Bangladesh. Using a structured questionnaire, they found a positive and significant impact of CSR on financial performance, in what concerns fair pay and labour rights, and the environment and occupational health \& safety CSR dimensions.

Pavelkova et al. (2021) evaluated the impact of agglomeration and clustering on financial performance of textiles firms. The authors used financial indicators, such as ROA, ROS, labour productivity and Economic Value Added, applied to Czech textile industry, in 20092016. The results failed to confirm a significant influence of firm location on financial performance. They obtained the same results when investigating potential differences for firm's age and size.

\section{Methodology and data sources}

Firm's annual accounts, especially income statement and balance sheet, are the most relevant data to analyse firm's financial performance. It helps for the assessment of business strengths and weaknesses (Carmeli, 2002). Basically, analysts convert data from these statements into financial metrics - ratios, that assist in decision making, trying to respond to such questions as: How effectively has the firm performed, relative to its own past performance and/ or relative to its competitors? How is the firm liable to perform in the future? Grounded on expectations about future performance, what is the value of this firm?

Accounting information regarding profitability, liquidity, indebtedness, and growth is critical to measuring financial sustainability (Wu et al., 2010). Indeed, studies show that firms 
with relatively lower earnings, negative profits, larger declines in operating income, high indebtedness and few probabilities to growth are more likely to experience bankruptcy.

Thus, the objective of this paper is to analyse the economic sustainability of textile industry in France to provide policy implications.

According to (Steurer et al., 2005), economic sustainability is classified through its financial performance, competitiveness and the economic impact generated by the firm and its stakeholders. This research encompasses a numerical and narrative analysis of key financial ratios to 57 French firms (active in 2021) operating in the manufacturing of textiles (NACE Rev. 2 code 13), from 2018 to 2020.

Ratios are calculated to achieve an overall picture of firms' economic sustainability, namely profitability, liquidity, and indebtedness.

Profitability ratio analysis is a good approach to measure firm's performance, because it means the firm's ability to generate earnings. Firms' profitability is essential both for shareholders and creditors because profits allow for dividends and funds for covering debts. Examples include return on assets (ROA), return on equity (ROE), cash return on assets, return on debt, return on retained earnings, return on revenue, risk-adjusted return, return on invested capital, and return on capital employed. This paper employs ROE.

The ROE measures the firms' ability to generate profits using shareholders' investments. It is also known as shareholders' return. The calculation formula is as follows:

$$
R O E=\frac{\text { Net Income }}{\text { Total Equity }}
$$

This ratio shows how efficiently is the money from shareholders being used for the generation of earnings. In view of this, ROE, as well as ROA, should be positive, and a high value is desirable because that would mean efficiency in the use of investors' funds.

Liquidity ratios measure firms' ability to pay off current debt obligations without raising external capital. Examples of liquidity ratios are current ratio, quick ratio, and operating cash flow ratio. This paper uses the current ratio measured as:

$$
\text { Current Ratio }=\frac{\text { Current Assets }}{\text { Current Liabilities }}
$$

It measures firms' ability to pay off their current liabilities (payable within one year) with their current assets (cash, accounts receivable and inventories). It evaluates the coverage of short-term debts in an emergency. The higher the ratio, the better the firms' liquidity position. Although, if too high, it may mean that firms are not doing efficient investments (e.g., high value of trade receivables may lead to bad debts and not to operational cash flows).

Indebtedness ratios allow to understand firms' capital structure, being useful to assess long-term financial risk, since it provides information about firms' capacity to fulfil their long-term financial commitments. This paper uses the debt ratio.

When liabilities finance most of the assets, the firm is considered highly leveraged and is regarded as riskier for lenders. The debt ratio is calculated as:

$$
\text { Debt Ratio }=\frac{\text { Total Liabilities }}{\text { Total Assets }}
$$

This ratio helps investors and creditors to analyse the overall debt burden on the firm as well as the firm's ability to pay off the debt in the future. The highest the debt ratio, the highest the firm's risk since it has more obligations to pay back.

The ratio analysis is complemented by the assessment of the profit margin (Net Income/Turnover) and labour productivity (Turnover/Number of Employees) of these firms.

Firms' financial reporting was collected from ORBIS Database, from Bureau van Dijk. Only private firms and active in 2021 were included. The final sample comprises 57 French firms for 3 years (from 2018 to 2020). 
From the 57 firms of the sample, only one is large, i.e., it has 250 or more employees, all the others are considered micro (14 firms with less than 10 employees) or SME (Small and Medium Enterprises) with less than 250 employees (42 firms).

\section{Results and discussion}

To understand the economic sustainability of this industry, a set of indicators, namely of profitability, liquidity and indebtedness were used. Table 1 presents the descriptive statistics of the ratios calculated, namely mean, standard deviation, minimum and maximum.

Table 1. Financial statistics

\begin{tabular}{|c|c|c|c|c|c|}
\hline Ratio & Obs. & Mean & Std. Dev. & Min & Max \\
\hline ROE & 159 & 7 & 32 & -121 & 171 \\
\hline Liquidity & 170 & 3 & 3 & 0 & 19 \\
\hline Debt & 170 & 52 & 30 & 6 & 192 \\
\hline Profit margin & 166 & 1 & 10 & -63 & 16 \\
\hline Labour productivity & 169 & 289 & 800 & 2 & 10416 \\
\hline
\end{tabular}

Source: Author's calculations using Stata 17.0

According to Table 1, French textile firms' ROE is positive on average (7). However, there is a great dispersion among the sample $(\mathrm{sd}=32)$. The liquidity ratio is higher than the unity, suggesting that firms can pay their short-term debts with their current assets. The dispersion among the sample is also high $(\mathrm{sd}=30)$ The indebtedness is $52 \%$, on average, meaning that liabilities are the main source to finance the firm's investment.

To assess the impact of COVID-19 on textile industry, the sample is split into years and firm size (micro, small and medium and large firms). Table 2 shows the results for the ratio analysis. According to Table 2, there are great differences in the financial ratio's values among firms according to size and year. By and large firms in the 3rd quartile are much better off regarding profitability, liquidity and indebtedness, profit margins and productivity, than firms in other quartiles, showing a great dispersion of financial performances,

Concerning micro enterprises, the financial profitability and liquidity have decreased with the pandemic, while indebtedness increased. However, the profit margin and the labour productivity have increased.

As far as SMEs are concerned, although the financial profitability has decreased in 2020, compared to 2019; the liquidity has remained the same and the indebtedness was reduced. However, the profit margins and labour productivity have dropped in 2020.

In what concerns the large textiles firm, the financial profitability increased, the liquidity remained in 2019's level at expenses of an increase in debt, the profit margin has shrunken but the labour productivity has increased. 
Table 2. Financial statistics by year and firms' size

\begin{tabular}{|c|c|c|c|c|c|c|}
\hline & & $R O E$ & liquidity & Debt & $\begin{array}{c}\text { Profit } \\
\text { Margin }\end{array}$ & $\begin{array}{c}\text { Labour } \\
\text { Productiviity }\end{array}$ \\
\hline & & \multicolumn{5}{|c|}{ Panel A: Micro entreprises } \\
\hline \multirow{3}{*}{$\stackrel{\infty}{\stackrel{\sim}{\sim}}$} & 1st Quartile & -4 & 2 & 26 & -13 & 131 \\
\hline & Median & 12 & 3 & 42 & 5 & 171 \\
\hline & 3rd Quartile & 24 & 4 & 50 & 9 & 225 \\
\hline \multirow{3}{*}{ हे } & 1st Quartile & 6 & 2 & 31 & 3 & 105 \\
\hline & Median & 18 & 2 & 43 & 7 & 167 \\
\hline & 3rd Quartile & 37 & 4 & 57 & 9 & 236 \\
\hline \multirow{4}{*}{ ્ָరి } & 1st Quartile & 1 & 2 & 33 & -1 & 126 \\
\hline & Median & 12 & 2 & 56 & 3 & 216 \\
\hline & 3rd Ouartile & 20 & 3 & 65 & 13 & 292 \\
\hline & & \multicolumn{5}{|c|}{ Panel B: SMES } \\
\hline \multirow{3}{*}{$\stackrel{\infty}{\stackrel{2}{i}}$} & 1st Quartile & 0 & 2 & 37 & -2 & 123 \\
\hline & Median & 7 & 2 & 53 & 3 & 180 \\
\hline & 3rd Quartile & 20 & 3 & 63 & 5 & 336 \\
\hline \multirow{3}{*}{ 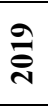 } & 1st Quartile & -3 & 1 & 37 & -4 & 117 \\
\hline & Median & 7 & 2 & 46 & 2 & 164 \\
\hline & 3rd Quartile & 17 & 3 & 68 & 6 & 348 \\
\hline \multirow{4}{*}{ ฮิ } & 1st Quartile & -7 & 2 & 35 & -3 & 105 \\
\hline & Median & 0 & 2 & 46 & 0 & 151 \\
\hline & 3rd Quartile & 13 & 3 & 60 & 5 & 274 \\
\hline & & \multicolumn{5}{|c|}{ Panel C Large Entreprises } \\
\hline \multirow{3}{*}{$\stackrel{\infty}{\stackrel{\sim}{~}}$} & 1st Quartile & 13 & 2 & 62 & 6 & 367 \\
\hline & Median & 13 & 2 & 62 & 6 & 367 \\
\hline & 3rd Quartile & 13 & 2 & 62 & 6 & 367 \\
\hline \multirow{3}{*}{ 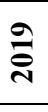 } & 1st Quartile & 9 & 2 & 65 & 3 & 340 \\
\hline & Median & 9 & 2 & 65 & 3 & 340 \\
\hline & 3rd Quartile & 9 & 2 & 65 & 3 & 340 \\
\hline \multirow{3}{*}{ ָิ } & 1st Quartile & 19 & 2 & 73 & 5 & 443 \\
\hline & Median & 19 & 2 & 73 & 5 & 443 \\
\hline & 3rd Quartile & 19 & 2 & 73 & 5 & 443 \\
\hline
\end{tabular}

Source: Own analysis in Stata 17.0

Comparing the average performance by firm size, the following results emerge during the pandemic: 1) micro enterprises show better financial profitability, followed by the large firm; 2) However, regarding the liquidity, micro and SMEs are better off than the large firm; 3) SMEs are less indebted and the larger firm has the highest level of indebtedness; 4) micro enterprises were more capable to increase their profit margins; 5) the larger firm shows a higher level of labour productivity, followed by the micro enterprises. In conclusion, French textiles micro enterprises appear to be more economically sustainable during the pandemic. This might suggest that very small firms are more resilient and flexible, capable to adapt their operations to market's needs.

The focus of this paper is to analyse the economic sustainability of French textile industry during the pandemic. For this purpose, firms' financial situation was analysed for 2018-202. However, the economic effectiveness does not warrant ecologic and social sustainability because the financial indicators do not reflect it. Consequently, the assessment of sustainable development needs an integrated approach, i.e., a set of multi-dimensional indicators, which evaluate both separate parts of the system and their relationships. Some studies (e.g., Elliot et al., 2014; Gao et al., 2014; Friedman et al., 2015; Gregory et al., 2016) might encourage a more complete analysis where social and environmental performance were analysed and compared to financial performance. Moreover, there is an inconsistency regarding the future development of sustainability assessment tools. In fact, on the one hand it is required a more specific assessment performance approach, i.e., more case- and site-specific; and on the other 
hand, there is a demand for broader tools for differing case circumstances. In addition, there is also the need for more standardized tools that give more transparent results.

Modern society need to pursue clear goals of sustainability that can be measured by sustainability indicators. Because sustainability indicators are multi-dimensional, multidisciplinary indices, often context-specific, there is no single broad measure of sustainable development. Hence sustainable indicators' development involves a methodological compromise among consistency, technical feasibility, and data availability (Ness et al., 2007). Following Pastille (2002), financial sustainability indicators should allow to: identify key elements of sustainable development and show the state of local sustainability; supporting decisions; involving stakeholders; directing to provide feedback on progress; and solving conflict and building consensus by showing the advantages and disadvantages of different alternatives.

\section{Conclusions and policy implications}

This paper uses key financial indicators in 2018-2020, to evaluate the economic sustainability of French textile industry during the pandemic. The results indicate that micro enterprises have better financial profitability, liquidity and appear to be more capable to increase their profit margins, in a period of a drop in demand, and increase their labour productivity. This might suggest that very small firms are more flexible, resilient, and capable to quickly adapt their operations to market's needs.

Financial analysis shows if a firm can get profit from its activity and to draw some conclusions on firms' ability to generate enough incomes to cover its costs and achieve a reasonable profit, i.e., to be economically and/or financially sustainable. Through the application of this financial performance measurement framework using a benchmarking methodology, it is possible to identify relatively strong and weak firms. The adoption of this framework of analysis can help policymakers to design industrial and regional policies with a view to early identification of those firms more economically sustainable.

Also, these findings can be used to investigate whether textile firms in France are resilient and can recover from the crisis caused by the COVID-19 pandemic. Results can also foster enhancements in the governance of textile industry in France.

Avenues of future research include using other indicators of financial and economic as well as environmental and social performance; and analyse the feasibility of the technologies at regional level and a multi-case study. Furthermore, similar analysis can be made to other European countries to corroborate the results.

\section{Acknowledgements}

This research is financed by National Funds of the FCT - Portuguese Foundation for Science and Technology within the project «UIDB/04928/2020».

\section{References}

1. Achille, A., \& Zipser, D. (2020). A perspective for the luxury-goods industry duringand after-coronavirus. McKinsey \& Company.

2. Al Masud, A., \& Islam, S. (2018). The relationship between corporate social responsibility (CSR) and financial performance of textiles sector in Bangladesh especially in Barisal Division. IJASSH. 
3. Araújo, R., Santos, G., da Costa, J. B., \& Sá, J. C. (2019). The quality management system as a driver of organizational culture: An empirical study in the Portuguese textile industry. Quality Innovation Prosperity, 23(1), 1-24.

4. Bose, I., Lui, A. K. H., \& Ngai, E. W. T. (2011). The Impact of RFID Adoption on the Market Value of Firms: An Empirical Analysis. Journal of Organizational Computing and Electronic Commerce, 21(4), 268-294.

5. Carmeli, A. (2002). A Conceptual and Practical Framework of Measuring Performance of Local Authorities in Financial Terms: Analysing the Case of Israel. Local Government Studies, 28(1), 21-36.

6. Chen, H., Frank, M.Z., \& Wu, O.Q. (2007). US retail and wholesale inventory performance from 1981 to 2004. Manuf. Serv. Oper. Manage, 9(4), 430-456.

7. Costa, C., Azoia, N., Silva, C., \& Marques, E. (2020). Textile Industry in a Changing World. Porto Journal of Engineering, 6(2), 86-97.

8. Desore, A., \& Narula, S. A. (2018). An overview on corporate response towards sustainability issues in textile industry. Environment. Development and Sustainability, 20(4), 1439-1459.

9. Dulange, S. R., Pundir, A. K., \& Ganapathy, L. (2014). Performance of Power Loom Textiles: A Resource-based View. International Journal of Innovative Research in Advanced Engineering, 1(6), 68-82.

10. Elliott, W. B., Jackson, K. E., Peecher, M. E., \& White, B. J. (2014). The Unintended Effect of Corporate Social Responsibility Performance on Investors' Estimates of Fundamental Value. The Accounting Review, 89, 275-302.

11. Friedman, H. L., \& Heinle, M. S. (2015). Taste, information, and asset prices: Implications for the valuation of CSR. Review of Accounting Studies, 1-35.

12. Fullerton, R.R., McWatters, C.S., \& Fawson, C. (2003). An examination of the relationships between JIT and financial performance. J. Oper. Manage, 21(4), 383-404.

13. Gao, F., Lisic, L. L., \& Zhang, I. X. (2014). Commitment to social good and insider trading. Journal of Accounting and Economics, 57(2-3), 149-175.

14. Gaur, V., Fisher, M.L., \& Raman, A. (2005). An econometric analysis of inventory turnover performance in retail services. Manage. Sci., 51(2), 181-194.

15. Gregory, A., Whittaker, J., \& Yan, X. (2016). Corporate Social Performance, Competitive Advantage, Earnings Persistence and Firm Value. Journal of Business Finance \& Accounting, 43(1-2), 3-30.

16. Huson, M., \& Nanda, D. (1995). The impact of just-in-time manufacturing on firm performance in the US. J. Oper. Manage., 12(3), 297-310.

17. International Textile Manufacturers Federation. (2020, June 18). 4th ITMF-Survey about the impact of the corona-pandemic on the global textile industry. https://www.itmf.org/images/dl/press-releases/2020/Cor ona-Survey-4th-2020.06.18Press-Release.pdf

18. Kozlowski, A., Searcy, C., \& Bardecki, M. (2018). The reDesign canvas: Fashion design as a tool for sustainability. Journal of Cleaner Production, 183, 194-207.

19. Lieberman, M.B., \& Demeester, L. (1999). Inventory reduction and productivity growth: linkages in the Japanese automotive industry. Manage. Sci., 45(4), 466-485.

20. Lo, C. K., Yeung, A. C., \& Cheng, T. C. E. (2012). The impact of environmental management systems on financial performance in fashion and textiles industries. International Journal of Production Economics, 135(2), 561-567. 
21. Lu, Y., Wu, J., Peng, J., \& Lu, L. (2020). The perceived impact of the Covid-19 epidemic: evidence from a sample of 4807 SMEs in Sichuan Province. China. Environmental Hazards, 19(4), 323-340.

22. McIntosh, S. (2020, April 30). Coronavirus: Why the fashion industry faces an "existential crisis." https://www.bbc.com/news/entertainment-arts-52394504.

23. Modi, S.B., \& Mishra, S. (2011). What drives financial performance-resource efficiency or resource slack? Evidence from US Based Manufacturing Firms from 1991 to 2006. J. Oper. Manage., 29(3), 254-273.

24. Ness, B., Urbel-Piirsalu, E., Anderberg, S., \& Olsson, L. (2007). Categorising tools for sustainability assessment. Ecological Economics, 60(3), 498-508.

25. Ntsalaze, L. (2013). The impact of family ownership on firms' performance: A study of firms in the South African Clothing and Textiles manufacturing industry 20092011 (Master's thesis, University of Cape Town).

26. Pastille Consortium (2002). Indicators into Action: Local Sustainability Indicator Sets in their Context. Final report.

27. Pavelkova, D., Zizka, M., Homolka, L., Knapkova, A., \& Pelloneova, N. (2021). Do clustered firms outperform the non-clustered? Evidence of financial performance in traditional industries. Economic Research-Ekonomska Istraživanja, 1-23.

28. Steinker, S., \& Hoberg, K. (2013). The impact of inventory dynamics on long-term stock returns-an empirical investigation of US manufacturing companies. J. Oper. Manage., 31(5), 250-261.

29. Steurer, R., Langer, M. E., Konrad, A., \& Martinuzzi, A. (2005). Corporations, stakeholders, and sustainable development: a theoretical exploration of business society relations. Journal of Business Ethics, 61(3), 263-281.

30. Wu, Y., Gaunt, C., \& Gray, S. (2010). A Comparison of Alternative Bankruptcy Prediction Models. Journal of Contemporary Accounting \& Economics, 6(1), 34-45.

31. Zhao, L., \& Kim, K. (2021). Responding to the COVID-19 Pandemic: Practices and strategies of the global clothing and Textile value chain. Clothing and Textiles Research Journal, 39(2), 157-172. 